\title{
Replication Association Study between RBC Indices and Genetic Variants in Korean Population
}

\author{
Sang In Lee ${ }^{*}$, Sangjung Park ${ }^{\dagger, * *}$ and Hyun-Seok Jin ${ }^{\dagger, * *}$ \\ Department of Biomedical Laboratory Science, College of Life and Health Sciences, \\ Hoseo University, Asan, Chungnam 31499, Korea
}

\begin{abstract}
Hemoglobin $(\mathrm{Hb})$ concentrations and hematocrit $(\mathrm{Hct})$ values can be changed by factors such as erythrocyte production, destruction, and bleeding. In addition, variants in the protein expression involved in the amount of red blood cells that determine $\mathrm{Hb}$ metabolism or Hct value can increase susceptibility to complex blood diseases. Previous studies have reported significant single nucleotide polymorphisms (SNPs) by applying a genome-wide association study (GWAS) on $\mathrm{Hb}$ levels and Hct values in European population. In this study, we confirmed whether the significant SNPs are replicated in Koreans. In previous studies, 26 and 18 SNPs with a significant correlation $\mathrm{Hb}$ and Hct were identified in Korean genotype data, and 21 and 12 SNPs were selected, respectively. The SNPs of PRKCE (rs10495928), TMPRSS6 (rs2235321, rs5756505, rs855791) were significantly associated with $\mathrm{Hb}(P<0.05)$. In the association analysis of Hct, the SNPs of HBS1L (rs6920211, rs9389268, rs9483788), PRKCE (rs4953318), SCGN (rs9348689) and TMPRSS6 (rs2413450) genes showed a significant correlation $(P<0.05)$. Replicated SNPs and not replicated SNPs showed the difference of genetic distance calculated by $F$ st. The replicated SNPs with a significant correlation showed similar allele frequencies, whereas the not replicated SNPs showed a large difference in allele frequency. All replicated SNPs with significant correlations had $F$ st values less than 0.05 , indicating that the genetic distance between the groups was close. On the other hand, the not replicated SNPs showed that the $F$ st value was 0.05 or more and the genetic distance was relatively large.
\end{abstract}

Key Words: Genetic association, Hematocrit, Hemoglobin, Single nucleotide polymorphism

Hemoglobin $(\mathrm{Hb})$ 은 적혈구에 존재하는 산소운반 단백질 이며, Hematocrit $(\mathrm{Hct})$ 은 혈액에서 적혈구가 차지하고 있는 용적의 비중을 백분율로 표시한 것이다. 혈구 조혈에 문 제가 생기거나 적혈구 파괴와 같은 질환이 발생하면 $\mathrm{Hb}$ 농도와 Hct 값이 비정상적 수치를 나타내게 된다. $\mathrm{Hb}$ 은 헴 구조에 2가 철 이온을 가지고 있을 때 산소운반 기능
을 하게 되는데, 이러한 과정에 관여하는 단백질 발현에 이상이 생길 경우에 기능적 $\mathrm{Hb}$ 의 수가 줄어들게 되어 빈 혈을 유발할 수 있다. 이러한 질환일 발생하게 되면 질병 의 보상적 작용으로 기능적 $\mathrm{Hb}$ 의 보충을 위한 조혈작용 이 이루어지고 $\mathrm{Hb}$ 농도와 $\mathrm{Hct}$ 값이 정상보다 상승하게 된다. $\mathrm{Hb}$ 과 $\mathrm{Hct}$ 수치의 상승은 혈액의 점도를 증가시켜

Received: June 14, 2019 / Revised: July 1, 2019 / Accepted: July 2, 2019

* Graduate student, ${ }^{* *}$ Professor.

${ }^{\dagger}$ These authors are equally contributed.

${ }^{\dagger}$ Corresponding author: Sangjung Park. Department of Biomedical Laboratory Science, College of Life and Health Sciences, Hoseo University, Asan, Chungnam 31499, Korea.

Tel: +82-41-540-9967, Fax: +82-41-540-9997, e-mail: sangjung@hoseo.edu

$\dagger$ Corresponding author: Hyun-Seok Jin. Department of Biomedical Laboratory Science, College of Life and Health Sciences, Hoseo University, Asan, Chungnam 31499, Korea.

Tel: +82-41-540-9968, Fax:+82-41-540-9997, e-mail: jinhs@hoseo.edu

(C)The Korean Society for Biomedical Laboratory Sciences. All rights reserved.

@ (This is an Open Access article distributed under the terms of the Creative Commons Attribution Non-Commercial License (http://creativecommons.org/licenses/by-nc/3.0/) which permits unrestricted non-commercial use, distribution, and reproduction in any medium, provided the original work is properly cited. 
Table 1. Basic characteristics of the subjects in the KARE

\begin{tabular}{lc}
\hline \hline \multicolumn{1}{c}{ Characteristics } & Total \\
\hline Number of subjects & 8,840 \\
Age (M years $\pm \mathrm{SD})$ & $52.22 \pm 8.91$ \\
Gender [men (\%) / women (\%)] & $4182(47) / 4658(53)$ \\
Area [Anseong (\%) / Ansan (\%)] & $4205(48) / 4635(52)$ \\
Hemoglobin (M $\pm \mathrm{SD})$ & $13.58 \pm 1.60$ \\
Hematocrit $(\mathrm{M} \pm \mathrm{SD})$ & $41.02 \pm 4.60$ \\
\hline
\end{tabular}

Abbreviations: KARE, Korean association resource; M, mean value; $\mathrm{SD}$, standard deviation

혈관질환을 유발할 수 있다. 따라서 $\mathrm{Hb}$ 농도와 $\mathrm{Hct}$ 값과 관련된 단백질의 변화는 혈액관련 복합질환에 대한 감수 성을 증가시킬 수 있다고 알려져 있다(Amr et al., 2019; Grimholt et al., 2019; Paradowska-Gorycka et al., 2019).

Zhong et al.은 유럽인을 대상으로 $\mathrm{Hb}$ 과 $\mathrm{Hct}$ 에 대한 전 장 유전체 분석연구(Genome-wide association study, GWAS) 를 시행하여 유의성 있는 SNP (Single Nucleotide Polymorphisms)들을 발표하였다(Zhong et al., 2016). $\mathrm{Hb}$ 농도와의 상관 분석에서 $H F E$ 유전자의 $\operatorname{rs} 1800562\left(P=1.06 \times 10^{-15}\right)$, HISTIHIC 유전자의 rs9295685 $\left(P=4.11 \times 10^{-13}\right)$ 포함 총 18 유전자 내 $26 \mathrm{SNP}$ 에서 통계적 유의성이 확인되었다. Hct 값과의 상관 분석에서는 $P R K C E$ 유전자의 $\mathrm{rs} 4953318(P=$ $\left.1.18 \times 10^{-12}\right), H B S 1 L$ 유전자의 $\mathrm{rs} 9483788\left(P=3.55 \times 10^{-11}\right)$ 포 함하여 총 14 개 유전자 영역 내 18 개의 SNP에서 통계적 유의성이 확인되었다. 따라서 본 연구에서는 유럽인 코호 트를 대상으로 $\mathrm{Hb}, \mathrm{Hct}$ 와 연관되어 있는 유전자 유전적 다형성의 유의한 상관 관계가 한국인 대상의 유전체 역 학 코호트를 기반으로 분석하였을 때에도 재현성이 있는 지를 확인하고자 하였다.

선행된 연구에서 $\mathrm{Hb}, \mathrm{Hct}$ 에 대해 전장 유전체 분석은 Cohorts for Heart and Aging Research in Genomic Epidemiology (CHARGE) consortium(유럽인 계통 24,167명)과 HaemGen Consortium(유럽인 계통 9,456명)을 기반으로 하 였다(Ganesh et al., 2009; Soranzo et al., 2009). Hb 수치와의 상관 분석에서 높은 유의수준 $\left(P \leq 5 \times 10^{-8}\right)$ 을 만족하는 $\mathrm{SNP}$ 이 26 개였고, Hct에서는 18 개의 SNP들이 GWAS 유의수준 을 만족하고 있었다(Zhong et al., 2016). 상관 분석 시 $\mathrm{Hb}$ 농도와 Hct 값을 상승하는 방향으로 영향을 주는 allele를 effect allele로 지정하였다.

본 연구를 위한 한국인 연구대상자는 한국인 유전체 역학 조사 사업(Korean Genome and Epidemiology Study;
KoGES)의 일환인 Korean Association Resource (KARE)를 대상으로 하였다(Cho et al., 2009). 이때 이용한 자료는 질 병관리본부 인체자원은행에서 분양을 받아 사용하였다. 총 남녀 10,038명 중 QC (Quality Control) 과정을 통과한 8,840 명을 선정하였다(Table 1). 본 연구에 활용한 유전 정보는 질병관리본부 $(\mathrm{KNIH})$ 와 호서대학교에서 연구윤리 승인을 받은 후 분석을 수행하였다(1041231-170822-BR062-01).

한국인의 SNP 정보는 KARE 유전형 자료를 기반으로 하였다. DNA 시료는 연구 참여자의 말초혈액에서 분리 추출하였고, 유전형 판독을 위해서는 Affymetrix GenomeWide Human SNP array 5.0 (Affymetrix, Inc., Santa Clara, CA, $\mathrm{USA}$ )를 사용하였다. 유전형 판독 정확도가 $98 \%$ 이하이거 나, $4 \%$ 이상의 높은 missing genotype call rate을 보이거나, $30 \%$ 초과의 heterozygosity를 가지거나, 성별 불일치가 존 재하는 대상자들은 제외되었다. SNP들의 염색체 상의 위 치는 UCSC Genome Browser on Human Feb. 2009 (GRCh37/ $\mathrm{hg} 19)$ 를 기준으로 하였다. 또한, 실제 실험적으로 SNP의 유전형을 확인한 것 이외에도 해당되는 유전좌위 영역 에서는 MACH 1.0.16 (Li et al., 2010)를 사용하여 추가적으 로 imputation SNP을 발굴하여 분석에 사용하였다. 본 연 구의 Imputation에 사용한 기본 정보는 HapMap database (release 24) (International HapMap Consortium 2003)에서 중 국인(Han Chinese form Beijing)과 일본인(Japanese in Tokyo) 의 것을 참고로 진행하였다.

대부분의 통계 분석에는 PLINK version 1.07 (http://pngu.mgh.harvard.edu/ purcell/plink)과 PASW Statistics version 18.0 (SPSS Inc. Chicago, IL, USA)을 사용하였다. Hb과 Hct에 대 한 유전적 변이의 상관성 분석은 선형 회귀 분석을 사용 하였으며 additive genetic model을 기반으로 하였다. 회귀 분석의 시행에 있어서 나이, 지역, 성별을 공변수로 처리 하여 분석하였다. 분석 값에 대한 유의수준은 0.05 미만 을 기준으로 하였다. 또한 분석 시 기준이 되는 allele는 선행된 연구와 동일한 것으로 하였다.

Zhong et al.에서 $\mathrm{Hb}$ 와 통계적으로 유의한 SNP은 26개 였으며 Hct과 통계적으로 유의한 SNP은 18 개였다. 이 $\mathrm{SNP}$ 들을 한국인 코호트 SNP 정보에서 확인해 보았을 때, $\mathrm{Hb}$ 에서는 26 개의 SNP 중 21 개의 SNP이 분석 가능하였 다. 또한 Hct에서는 18 개의 $\mathrm{SNP}$ 중 12 개의 SNP이 분석에 사용되었다. 이러한 방식으로 한국인 코호트에서 선별된 $\mathrm{SNP}$ 들과 $\mathrm{Hb}$ 농도, $\mathrm{Hct}$ 값에 대한 상관성 분석을 진행하 였다(Table 2). 
Table 2. Replication results of linear regression analyses for RBC indices in Korean population and comparison of $F$ st for between two population

\begin{tabular}{|c|c|c|c|c|c|c|c|c|c|}
\hline \multirow{2}{*}{ Gene } & \multirow{2}{*}{ SNP } & \multirow{2}{*}{ EA } & \multicolumn{3}{|c|}{ European } & \multicolumn{3}{|c|}{ Korean } & \multirow[b]{2}{*}{$F$ st } \\
\hline & & & $\mathrm{EAF}$ & beta & $P$-value & EAF & beta & $P$-value & \\
\hline \multicolumn{10}{|c|}{ Hemoglobin } \\
\hline ATXN2 & rs10774625 & $\mathrm{A}$ & 0.477 & 0.0612 & $1.44 \times 10^{-9}$ & 0.022 & 0.0275 & 0.648 & 0.277 \\
\hline$B R A P$ & rs11065987 & $\mathrm{G}$ & 0.419 & 0.0671 & $1.32 \times 10^{-8}$ & 0.025 & -0.0163 & 0.770 & 0.224 \\
\hline HISTIHIA & rs9393681 & $\mathrm{C}$ & 0.456 & 0.0717 & $6.95 \times 10^{-11}$ & 0.785 & 0.0006 & 0.977 & 0.115 \\
\hline HISTIHIC & rs9295685 & $\mathrm{C}$ & 0.400 & 0.0887 & $4.11 \times 10^{-13}$ & 0.737 & -0.0075 & 0.704 & 0.116 \\
\hline HISTIHIT & rs198833 & $\mathrm{G}$ & 0.178 & 0.0970 & $9.48 \times 10^{-10}$ & 0.046 & 0.0142 & 0.732 & 0.043 \\
\hline LRRC16 & rs17492120 & $\mathrm{T}$ & 0.104 & 0.0969 & $1.65 \times 10^{-8}$ & 0.037 & -0.0058 & 0.899 & 0.017 \\
\hline \multirow{2}{*}{ MPST } & rs 5750373 & A & 0.414 & 0.0581 & $2.10 \times 10^{-8}$ & 0.684 & 0.0362 & 0.051 & 0.074 \\
\hline & rs8141597 & $\mathrm{C}$ & 0.347 & 0.0638 & $1.47 \times 10^{-8}$ & 0.659 & 0.0267 & 0.144 & 0.097 \\
\hline PRKCE & rs10495928 & $\mathbf{A}$ & 0.683 & 0.0744 & $7.58 \times 10^{-10}$ & 0.807 & 0.0650 & $3.08 \times 10^{-3}$ & $2.01 \times 10^{-2}$ \\
\hline \multirow[t]{3}{*}{ PTPN11 } & rs11066301 & $\mathrm{G}$ & 0.427 & 0.0630 & $1.29 \times 10^{-9}$ & 0.028 & -0.0709 & 0.180 & 0.226 \\
\hline & rs9348689 & $\mathrm{T}$ & 0.552 & 0.0839 & $3.80 \times 10^{-11}$ & 0.659 & -0.0357 & 0.056 & 0.012 \\
\hline & rs932316 & $\mathrm{C}$ & 0.438 & 0.0788 & $4.76 \times 10^{-9}$ & 0.139 & 0.0204 & 0.416 & 0.109 \\
\hline \multirow[t]{4}{*}{$S C G N$} & rs1321247 & $\mathrm{T}$ & 0.176 & 0.1209 & $1.12 \times 10^{-9}$ & 0.034 & 0.0284 & 0.550 & 0.054 \\
\hline & rs2205936 & $\mathrm{C}$ & 0.552 & 0.0686 & $9.15 \times 10^{-9}$ & 0.730 & -0.0101 & 0.604 & 0.034 \\
\hline & rs9467556 & $\mathrm{C}$ & 0.147 & 0.0793 & $9.61 \times 10^{-9}$ & 0.133 & 0.0267 & 0.296 & $3.84 \times 10^{-4}$ \\
\hline & rs2235321 & $\mathbf{A}$ & 0.424 & 0.0614 & $1.11 \times 10^{-8}$ & 0.494 & 0.0838 & $1.58 \times 10^{-6}$ & $4.91 \times 10^{-3}$ \\
\hline \multirow[t]{2}{*}{ TMPRSS6 } & rs5756505 & $\mathbf{C}$ & 0.432 & 0.0639 & $3.99 \times 10^{-10}$ & 0.499 & 0.0837 & $1.30 \times 10^{-6}$ & $4.52 \times 10^{-3}$ \\
\hline & rs855791 & $\mathbf{G}$ & 0.612 & 0.0944 & $1.40 \times 10^{-15}$ & 0.506 & 0.0800 & $4.64 \times 10^{-6}$ & $1.14 \times 10^{-2}$ \\
\hline TRAFDI & rs 17630235 & A & 0.410 & 0.0663 & $5.70 \times 10^{-10}$ & 0.031 & -0.0456 & 0.370 & 0.209 \\
\hline TRIM38 & rs12216125 & $\mathrm{T}$ & 0.359 & 0.0810 & $1.55 \times 10^{-11}$ & 0.121 & 0.0215 & 0.421 & 0.078 \\
\hline TSHZ2 & rs6013509 & $\mathrm{G}$ & 0.750 & 0.0699 & $1.96 \times 10^{-9}$ & 0.661 & 0.0187 & 0.308 & $9.63 \times 10^{-3}$ \\
\hline \multicolumn{10}{|c|}{ Hematocrit } \\
\hline$\overline{A T X X N 2}$ & rs10774625 & $\mathrm{A}$ & 0.477 & $\begin{array}{l}0.1702 \\
\end{array}$ & $4.88 \times 10^{-10}$ & 0.022 & 0.1859 & 0.286 & 0.277 \\
\hline \multirow[t]{2}{*}{$B R A P$} & rs11065987 & $\mathrm{G}$ & 0.419 & 0.1809 & $3.34 \times 10^{-10}$ & 0.025 & 0.1340 & 0.409 & 0.224 \\
\hline & rs6920211 & $\mathbf{T}$ & 0.736 & 0.2096 & $6.96 \times 10^{-11}$ & 0.653 & 0.2569 & $1.21 \times 10^{-6}$ & $8.19 \times 10^{-3}$ \\
\hline \multirow[t]{2}{*}{ HBSIL } & rs9389268 & $\mathbf{A}$ & 0.749 & 0.1978 & $1.60 \times 10^{-10}$ & 0.680 & 0.3451 & $1.53 \times 10^{-10}$ & $5.83 \times 10^{-3}$ \\
\hline & rs9483788 & $\mathbf{T}$ & 0.765 & 0.2172 & $3.55 \times 10^{-11}$ & 0.673 & 0.2247 & $3.38 \times 10^{-5}$ & $1.04 \times 10^{-2}$ \\
\hline \multirow{2}{*}{ PRKCE } & rs10184620 & $\mathrm{A}$ & 0.911 & 0.2834 & $7.23 \times 10^{-9}$ & 0.987 & 0.3259 & 0.128 & 0.029 \\
\hline & rs4953318 & $\mathbf{A}$ & 0.627 & 0.2010 & $1.18 \times 10^{-12}$ & 0.778 & 0.2303 & $1.32 \times 10^{-4}$ & $2.73 \times 10^{-2}$ \\
\hline PTPN11 & rs11066301 & $\mathrm{G}$ & 0.427 & 0.1647 & $3.97 \times 10^{-9}$ & 0.028 & -0.1055 & 0.491 & 0.226 \\
\hline SCGN & rs9348689 & $\mathbf{T}$ & 0.552 & 0.1782 & $1.28 \times 10^{-8}$ & 0.659 & -0.1304 & $1.62 \times 10^{-2}$ & $1.19 \times 10^{-2}$ \\
\hline TFR2 & rs7385804 & $\mathrm{C}$ & 0.378 & 0.1592 & $2.75 \times 10^{-8}$ & 0.134 & 0.0196 & 0.791 & 0.078 \\
\hline TMPRSS6 & rs2413450 & $\mathrm{C}$ & 0.581 & 0.1620 & $6.33 \times 10^{-9}$ & 0.500 & 0.1858 & $2.14 \times 10^{-4}$ & $6.69 \times 10^{-3}$ \\
\hline TRAFDI & rs11066188 & $\mathrm{A}$ & 0.410 & 0.1748 & $1.21 \times 10^{-9}$ & 0.031 & 0.0467 & 0.753 & 0.209 \\
\hline
\end{tabular}

The replicated SNPs are indicated in bold. Abbreviations: SNP, single nucleotide polymorphism; EA, effect allele; EAF, effect allele frequency; $F$ st, $F$-statistics

$\mathrm{Hb}$ 수치와의 상관성 분석에서 $P R K C E$ (rs10495928), 유의한 상관 관계 $(P<0.05)$ 로 나타났다(Table 2). 이 SNP TMPRSS6 (rs2235321, rs5756505, rs855791) 유전자의 SNP이 중 rs5756505이 $\mathrm{Hb}$ 수치와 가장 높은 유의수준 $(P=1.30 \times$ 
(A) Hemoglobin

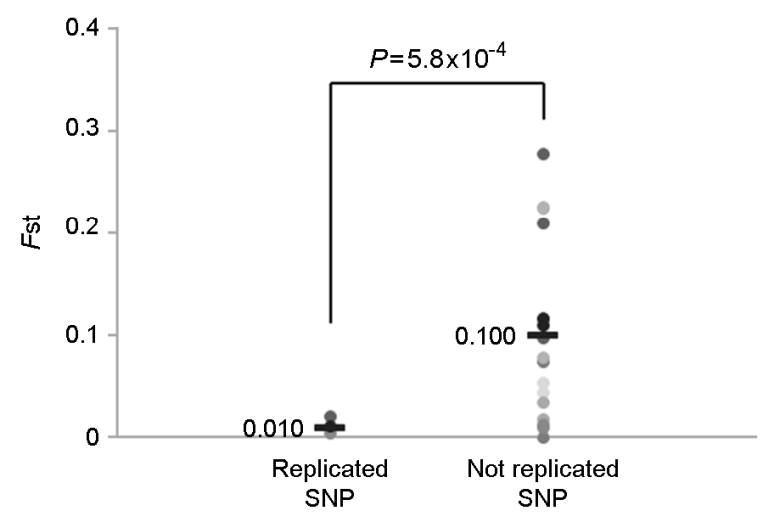

(B) Hematocrit

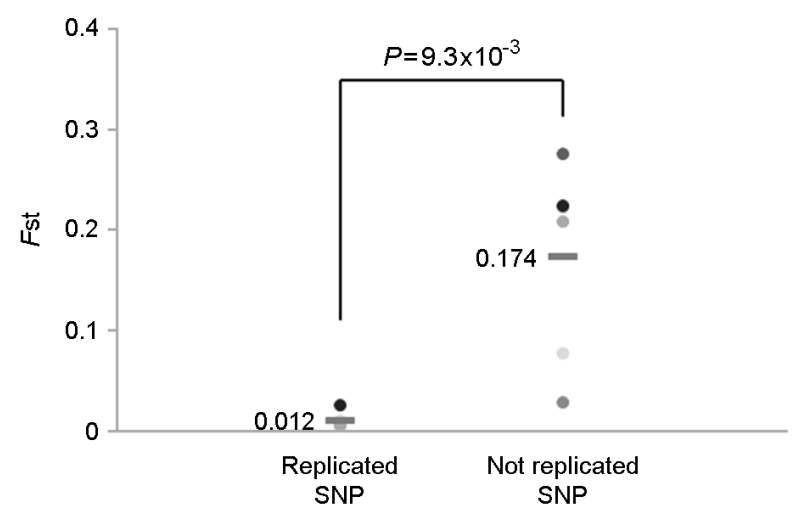

Fig. 1. Fst result of between European population SNPs and Korean population SNPs. Mean $F$ st is line (A), line (B). The mean $F$ st value in hemoglobin results (A) is 0.010 for replicated SNPs and 0.100 for not replicated SNPs. The mean $F$ st value in hematocrit results (B) is 0.012 for replicated SNPs and 0.174 for not replicated SNPs. Above $P$ value is t-test between mean $F$ st value. Abbreviations: SNP, single nucleotide polymorphism; $F$ st, F-statistics.

$\left.10^{-6}\right)$ 을 보여주었다. 유럽인 코호트와 마찬가지로 $4 \mathrm{SNP}$ 은 $\mathrm{Hb}$ 수치에 대한 effect allele를 보유하고 있을수록 $\mathrm{Hb}$ 수 치를 상승시키는 경향을 보여주었다.

$\mathrm{Hct}$ 수치와의 상관성 분석에서는 $H B S I L$ (rs6920211, rs9389268, rs9483788), PRKCE (rs4953318), SCGN (rs9348689), TMPRSS6 (rs2413450) 유전자의 SNP이 유의한 상관 관계 $(P<0.05)$ 로 나타났다(Table 2). 이 $\mathrm{SNP}$ 중 $\mathrm{rs} 9389268$ 이 Hct 값과 가장 높은 유의수준 $\left(P=1.53 \times 10^{-10}\right)$ 을 보여주었다. 한 편 유럽인 코호트에서 rs9348689은 Hct 수치에 대하여 effect allele를 보유할수록 Hct 수치가 상승하는 경향이었 지만 한국인 코호트에서는 effect allele 보유할수록 Hct 수 치가 감소하는 경향으로 유의한 결과가 나타났다. 그러나, 나머지 5개의 SNP은 유럽인 코호트와 마찬가지로 effect allele를 보유할수록 Hct 수치가 상승하는 경향으로 확인 되었다.

재현성을 보이는 $\mathrm{SNP}$ 들과 그렇지 않은 $\mathrm{SNP}$ 들 사이에 어떠한 차이가 있는지를 살펴보기 위해 우선적으로 두 개 의 인구 집단 간의 유전적 차이(Genetic distance)를 allele frequency로 비교하고, 이를 기반으로 $F \mathrm{st}$ 값을 산출하여 확인해보았다. $F \mathrm{st}$ 값은 $\mathrm{V}(\mathrm{q}) / \mathrm{q}(1-\mathrm{q})$ 로 계산하고 이 때, $\mathrm{V}(\mathrm{q})$ 는 유전자형빈도의 분산값이고 $\mathrm{q}$ 는 유전자형의 weighted frequency를 나타낸다. Fst는 0 1 사이의 값을 가지며 0에 가까울수록 집단의 유전적 분화가 적게 일어났음을 의미 하고 값이 커질수록 유전적 분화가 더 크게 일어났음을 의미한다. 우선, 유의한 결과로 재현된 SNP들은 유럽인
코호트와 한국인 코호트에서 effect allele frequency (EAF) 가 비슷한 빈도로 확인되었다(Table 2). 반면에, 재현되지 않은 SNP들은 재현된 SNP들과 비교하였을 때 유럽인 코 호트와 한국인 코호트의 $\mathrm{EAF}$ 차이가 분명하게 큰 것을 알 수 있었으며 크게는 $40 \%$ 이상 빈도의 차이가 있는 것 을 확인하였다. 따라서 유럽인 코호트와 한국인 코호트 사이의 인종 간 유전적 차이의 정도를 $F$ st ( $F$-statistics) 수 치로 확인하였다. $F \mathrm{st}$ 수치는 집단 간 유전 변이의 빈도 를 기반으로 하여 유전적 차이를 나타내는 값으로, 0.05 미만일 때 집단 간 유전적 거리가 가까운 것을 나타낸다. $\mathrm{Hb}$ 농도와 Hct 값에 대해 유의한 결과로 재현된 SNP들 은 Fst 값이 0.05 미만으로 확인되었다. TMPRSS6 유전자 의 rs5756505이 $\mathrm{Hb}$ 수치에 대해 유의한 결과를 나타낸 $\mathrm{SNP}$ 중 가장 유전적 차이가 적은 것으로 확인되었다 $(F \mathrm{st}=$ $4.52 \times 10^{-3}$ ). 또한 Hct 수치에 대한 분석에서는 $H B S I L$ 유 전자의 rs9389268이 가장 유전적 차이가 적은 것으로 확 인되었다 $\left(F \mathrm{st}=5.83 \times 10^{-3}\right)$. 추가적으로 한국인 코호트에서 재현된 $\mathrm{SNP}$, 재현되지 않은 $\mathrm{SNP}$ 의 $F \mathrm{st}$ 값과 평균을 $\mathrm{Hb}$, $\mathrm{Hct}$ 각각 도표로 나타냈다(Fig. 1). $\mathrm{Hb}$ 의 결과 재현된 $\mathrm{SNP}$ 의 평균 $F \mathrm{st}$ 값은 0.010 으로 유전적 거리가 가까운 것으 로 나타났고 재현되지 않은 $\mathrm{SNP}$ 의 평균 $F \mathrm{st}$ 값은 0.100 으 로 유전적 거리가 다소 먼 것을 확인했다. Hct의 결과 평 균 $F \mathrm{st}$ 값은 재현된 $\mathrm{SNP}$, 재현되지 않은 $\mathrm{SNP}$ 각각 0.012 , 0.174 로 확인되었고 $\mathrm{Hb}$ 의 결과와 비교했을 때 재현되지 않은 SNP들이 상대적으로 유전적 차이가 더 있는 것을 
알 수 있었다. 이 결과를 통해 한국인을 대상으로 $\mathrm{Hb}, \mathrm{Hct}$ 와 연관성이 재현된 SNP을 발굴할 수 있었으며 이렇게 재현성을 보인 SNP들은 두 인종 간 대립 유전자 빈도의 차이가 적다는 것을 알 수 있었고 재현되지 않은 SNP들 은 두 인종 간 유전적 차이가 상대적으로 큰 것으로 확인 되었다.

PRKCE, TMPRSS6는 $\mathrm{Hb}$ 농도와 Hct 값 모두 유의한 결 과로 재현되었다. $P R K C E$ 는 protein kinase $\mathrm{C}$ epsilon 단백 질을 발현하고 이것은 근육 수축을 조절하고 허혈성 손 상 및 심장 보호의 중심적인 역할을 하는 것으로 알려 져 있다(Jideama et al., 1996). TMPRSS6 유전자의 산물인 matriptase-2은 hepcidin의 발현을 조절함으로써 철의 항상 성을 조절하고 이 유전자의 변이형은 혈장 페리틴, $\mathrm{Hb}$, 철의 과부화에 영향을 주는 것으로 알려져 있다(Gan et al., 2012; Capra et al., 2017). Hct 값에 유의한 결과로 재현된 $H B S I L$ 은 $\mathrm{Hb} \mathrm{F}$ 농도에 영향을 주고 변이형은 sickle cell disease를 유발할 수 있으며(Menzel and Thein 2019). SCGN 은 칼슘 결합 단백질인 secretagogin을 발현하여 세포 증 식에 관여한다.

최근 특정 질병 또는 표현형과 유전적 다형성 사이에 상관 관계를 분석하여 질병 발병이 유전적으로 차이가 있을 수 있음을 제시하는 연구들이 활발히 진행되고 있 다(Pandit et al., 2008; Choi et al., 2012; Wu et al., 2013; Jin et al., 2018; Ko and Jin, 2019). 이번 연구에서 적혈구 수치와의 재현성이 확인된 유전자들에 대한 연구 또한 활발히 진행 되어 왔다(Chen et al., 2013; Capra et al., 2017; Pinto et al., 2017; Menzel and Thein, 2019). 이번 연구는 기존에 유럽인 코호트를 대상으로 수행하였던 적혈구 수치와 관련 있는 유전자의 유전적 다형성이 한국인 코호트에서도 동일하게 재현되는지 확인하고 하였다. 이번 연구의 결과는 일부 유 전자에서 유전적 다형성과 적혈구 수치의 상관 관계가 인 종에 따라 차이가 있을 수 있다는 것을 말해주고 있다. 또 한 한국인 대상으로 $\mathrm{Hb}$ 농도와 $\mathrm{Hct}$ 값에 대해 상관 관계 가 있는 SNP을 활용하여 혈액관련 복합질환의 이해와 치 료 및 예방에 활용할 수 있을 것으로 생각된다.

\section{ACKNOWLEDGEMENT}

This research was supported by Basic Science Research Program through the National Research Foundation of Korea (NRF) grant to HS. J (NRF-2017R1D1A3B03034752) funded by the Ministry of Education. This study was conducted with bioresources from National Biobank of Korea, the Centers for
Disease Control and Prevention, Republic of Korea (KBN2017-046).

\section{CONFLICT OF INTEREST}

The authors declare that they have no competing interests.

\section{REFERENCES}

Amr K, Pawlikowska P, Aoufouchi S, Rosselli F, El-Kamah G. Whole exome sequencing identifies a new mutation in the SLC19A2 gene leading to thiamine-responsive megaloblastic anemia in an Egyptian family. Mol Genet Genomic Med. 2019: e777.

Capra AP, Ferro E, Cannavo L, La Rosa MA, Zirilli G. A child with severe iron-deficiency anemia and a complex TMPRSS6 genotype. Hematology. 201.7 22: 559-564.

Chen Z, Tang H, Qayyum R, Schick UM, Nalls MA, Handsaker R, Li J, Lu Y, Yanek LR, Keating B, Meng Y, van Rooij FJ, Okada Y, Kubo M, Rasmussen-Torvik L, Keller MF, Lange L, Evans M, Bottinger EP, Linderman MD, Ruderfer DM, Hakonarson H, Papanicolaou G, Zonderman AB, Gottesman O, BioBank Japan Project, CHARGE Consortium, Thomson C, Ziv E, Singleton AB, Loos RJ, Sleiman PM, Ganesh S, McCarroll S, Becker DM, Wilson JG, Lettre G, Reiner AP. Genome-wide association analysis of red blood cell traits in African Americans: the COGENT Network. Hum Mol Genet. 2013. 22: 2529-2538.

Cho YS, Go MJ, Kim YJ, Heo JY, Oh JH, Ban HJ, Yoon D, Lee MH, Kim DJ, Park M, Cha SH, Kim JW, Han BG, Min H, Ahn Y, Park MS, Han HR, Jang HY, Cho EY, Lee JE, Cho NH, Shin C, Park T, Park JW, Lee JK, Cardon L, Clarke G, McCarthy MI, Lee JY, Lee JK, Oh B, Kim HL. A large-scale genome-wide association study of Asian populations uncovers genetic factors influencing eight quantitative traits. Nat Genet. 2009. 41: 527-534.

Choi HS, Yang HR, Song SH, Seo JY, Lee KO, Kim HJ. A novel mutation Gly603Arg of TMPRSS6 in a Korean female with iron-refractory iron deficiency anemia. Pediatr Blood Cancer. 2012. 58: 640-642.

Gan W, Guan Y, Wu Q, An P, Zhu J, Lu L, Jing L, Yu Y, Ruan S, Xie D, Makrides M, Gibson RA, Anderson GJ, Li H, Lin X, Wang F. Association of TMPRSS6 polymorphisms with ferritin, hemoglobin, and type 2 diabetes risk in a Chinese Han population. Am J Clin Nutr. 2012. 95: 626-632. 
Ganesh SK, Zakai NA, van Rooij FJ, Soranzo N, Smith AV, Nalls MA, Chen MH, Kottgen A, Glazer NL, Dehghan A, Kuhnel B, Aspelund T, Yang Q, Tanaka T, Jaffe A, Bis JC, Verwoert GC, Teumer A, Fox CS, Guralnik JM, Ehret GB, Rice K, Felix JF, Rendon A, Eiriksdottir G, Levy D, Patel KV, Boerwinkle E, Rotter JI, Hofman A, Sambrook JG, Hernandez DG, Zheng G, Bandinelli S, Singleton AB, Coresh J, Lumley T, Uitterlinden AG, Vangils JM, Launer LJ, Cupples LA, Oostra BA, Zwaginga JJ, Ouwehand WH, Thein SL, Meisinger C, Deloukas P, Nauck M, Spector TD, Gieger C, Gudnason V, van Duijn CM, Psaty BM, Ferrucci L, Chakravarti A, Greinacher A, O'Donnell CJ, Witteman JC, Furth S, Cushman M, Harris TB, Lin JP. Multiple loci influence erythrocyte phenotypes in the CHARGE Consortium. Nat Genet. 2009. 41: 1191-1198.

Grimholt RM, Fjeld B, Selsas H, Schwettmann L, Klingenberg O. Hb Aalesund (HBA2: c.400_406delAGCACCG), an Unstable alpha-Globin Variant Found in a Norwegian Patient Causing Moderate Hemolytic Anemia and Falsely High $\mathrm{Hb}$ A1c Using Ion Exchange High PerformanceLiquid Chromatography. Hemoglobin. 2019. 30:1-4.

Jideama NM, Noland TA, Jr, Raynor RL, Blobe GC, Fabbro D, Kazanietz MG, Blumberg PM, Hannun YA, Kuo JF. Phosphorylation specificities of protein kinase $\mathrm{C}$ isozymes for bovine cardiac troponin I and troponin $\mathrm{T}$ and sites within these proteins and regulation of myofilament properties. J Biol Chem. 1996. 271: 23277-23283.

Jin HS, Lee SI, Park S. Association between ITGB2 Genetic Polymorphisms and Tuberculosis. Korean J Clin Lab Sci. 2018. 50: 118-125.

Ko B, Jin HS. MACROD2 Polymorphisms Are Associated with Hypertension in Korean Population. Korean J Clin Lab Sci. 2019. 51: 57-63

Li Y, Willer CJ, Ding J, Scheet P, Abecasis GR. MaCH: using sequence and genotype data to estimate haplotypes and unobserved genotypes. Genet Epidemiol. 2010. 34: 816-834.

Menzel S, Thein SL. Genetic Modifiers of Fetal Haemoglobin in Sickle Cell Disease. Mol Diagn Ther. 2019. 23: 235-244.

Pandit RA, Svasti S, Sripichai O, Munkongdee T, Triwitayakorn K, Winichagoon P, Fucharoen S, Peerapittayamongkol C. Association of SNP in exon 1 of HBS1L with hemoglobin F level in beta0-thalassemia/hemoglobin E. Int J Hematol. 2008. 88: $357-361$

Paradowska-Gorycka A, Roszak M, Stypinska B, Lutkowska A, Walczyk M, Olesinska M, Wajda A, Piotrowski P, Puszczewicz
M, Majewski D, Jagodzinski PP. IL-6 and TGF-beta gene polymorphisms, their serum levels, as well as HLA profile, in patients with systemic lupus erythematosus. Clin Exp Rheumatol. 2019.

Pinto J, Nobre de Jesus G, Palma Anselmo M, Goncalves L, Bras D, Madeira Lopes J, Meneses J, Victorino R, Faustino P. Iron Refractory Iron Deficiency Anemia in Dizygotic Twins Due to a Novel TMPRSS6 Gene Mutation in Addition to Polymorphisms Associated With High Susceptibility to Develop Ferropenic Anemia. J Investig Med High Impact Case Rep. 2017. 5: 2324709617701776.

Soranzo N, Spector TD, Mangino M, Kuhnel B, Rendon A, Teumer A, Willenborg C, Wright B, Chen L, Li M, Salo P, Voight BF, Burns P, Laskowski RA, Xue Y, Menzel S, Altshuler D, Bradley JR, Bumpstead S, Burnett MS, Devaney J, Doring A, Elosua R, Epstein SE, Erber W, Falchi M, Garner SF, Ghori MJ, Goodall AH, Gwilliam R, Hakonarson HH, Hall AS, Hammond N, Hengstenberg C, Illig T, Konig IR, Knouff CW, McPherson R, Melander O, Mooser V, Nauck M, Nieminen MS, O'Donnell CJ, Peltonen L, Potter SC, Prokisch H, Rader DJ, Rice CM, Roberts R, Salomaa V, Sambrook J, Schreiber S, Schunkert H, Schwartz SM, Serbanovic-Canic J, Sinisalo J, Siscovick DS, Stark K, Surakka I, Stephens J, Thompson JR, Volker U, Volzke H, Watkins NA, Wells GA, Wichmann HE, Van Heel DA, Tyler-Smith C, Thein SL, Kathiresan S, Perola M, Reilly MP, Stewart AF, Erdmann J, Samani NJ, Meisinger C, Greinacher A, Deloukas P, Ouwehand WH, Gieger C. A genome-wide meta-analysis identifies 22 loci associated with eight hematological parameters in the HaemGen consortium. Nat Genet. 2009. 41: 1182-1190.

Wu Z, Miao M, Qiu Y, Qin Z, Wang J, Jiang Y, Ming Z, Zhang X. Association between polymorphisms in PDCD1 gene and aplastic anemia in Chinese Han population. Leuk Lymphoma. 2013. 54: 2251-2254.

Zhong Y, Lin SL, Schooling CM. The effect of hematocrit and hemoglobin on the risk of ischemic heart disease: A Mendelian randomization study. Prev Med. 2016. 91:351-353.

https://doi.org/10.15616/BSL.2019.25.2.190

Cite this article as: Lee SI, Park S, Jin HS. Replication Association Study between RBC Indices and Genetic Variants in Korean Population. Biomedical Science Letters. 2019. 25: 190-195. 